\title{
Systhesis and Characterization of Some Chromium (III) Schiff Base Complexes
}

\author{
KALPANA RAIKWAR ${ }^{1}$ and D.D. AGARWAL ${ }^{2}$ \\ 'Department of Chemistry, Government P.G. College, Guna - 473001, India. \\ ${ }^{2} \mathrm{SOS}$, Department of Chemistry, Jiwaji University, Gwalior - 474011, India. \\ ${ }^{*}$ Corresponding author E-mail: kalpanaraikwar45@gmail.com
}

http://dx.doi.org/10.13005/ojc/310168

(Received: November 30, 2014; Accepted: January 10, 2015)

\begin{abstract}
Chromium (III) Schiff base complexes have been synthesized using Schiff base formed by the condensing by the respective aldehyde with diamene in ethanol (rectified). All the complexes were characterized on the basis of their micro analytical data, elemental analysis, melting points, IR, UV- vis spectra and magnetic moment properties. The magnetic moment suggest that all the complexes are in the range 3.6-4.1 indicating the three unpaired electron. The infrared spectrum of the complexes under investigation confirmed the site of chelation, hence the complexes showed stretching due to $n(C=N)$ and $n(C-O)$ which suggest the involvement of phenolic group in the coordination. The UV-Vis spectral data shows the $\mathrm{p} \circledast \mathrm{p}^{*}$ transition which suggest to involves molecular orbital $p$ localized at the azomethane linkage.
\end{abstract}

Key word- Schiff bases, Salicylaldehyde, Characterization, IR, Magnetic moment, Dimethyl formamide.

\section{INTRODUCTION}

Schiff base complexes find important position in coordination chemistry and schiff base complexes with transition as well with heavy metals are used in organic synthesis, analytical reagents, and catalysts and in medicine ${ }^{1}$. Certain oxo metal complexes of $\mathrm{U}^{2,3}, \mathrm{OS}^{4,5}, \mathrm{~W}^{6}$ and $\mathrm{Cr}^{7,8}$ play an important role in organic synthesis because of their ability to selectively attach oxygen atom to olefins and other organic substrates. Recently metal catalyst of various organic oxidations effectively promoted chromium complexes acting via. their oxidation states, presumably chromium(III) has been reported $d^{9-13}$. Schiff base ligands ${ }^{14}$ are able to coordinate with metal through imine nitrogen and another group usually linked to the aldehyde. Infect Schiff bases are able to stabilize many different 
metals in various oxidation states, controlling the performance of metal and a large variety of useful catalytic transformations ${ }^{15,16}$. Chromium(III) complexes containing schiff bases and substituted benzimidazole / benzoxazole have attracted many workers ${ }^{17-19}$ due to their biological, pharmacological, clinical and analytical importance. The biologically important form of chromium is the trivalent ion, $\mathrm{Cr}^{+}$, which is required for carbohydrate and lipid metabolism in mammals ${ }^{20}$.

The coordination chemistry of Schiff bases derived from the reaction of salicylaldehyde and o-diamines has been the subject of many studies and a number of them are used as oxygen carriers to mimic complicated biological systems ${ }^{21,22}$. They are also efficient reagents in trace analysis of some metal cations ${ }^{23}$. Most of the Schiff bases are chemically unstable and show tendency to be involved in various equilibrium, like tautomeric inter conversions, hydrolysis or formation of ionized species $^{24}$.

\section{EXPERIMENTAL}

The material and reagents used in this study were laboratory pure chemical. The chemical components needed for the synthesis of desired schiff base complexes were chromium trioxide, thionyl chloride, salicylaldehyde, 1,3-diamino ethaane, ethylene diamine, p-cresol, 2-isopropyl phenol, 2-tert, butyl phenol, glycerol, boric acid, hexamine, ethanol, dichloro methane chloroform, methanol, dichloromethane, dimethyl formamide (DMF).

\section{Synthesis of Schiff base Ligands}

All the Schiff base ligands viz; bis(salicylaldehyde)1,2- diaminoethane $\left(\mathrm{H}_{2} \mathrm{SALEN}\right)$, bis (2-hydroxy-5-methyl benzaldehyde) 1,2diaminoethane $\left(\mathrm{H}_{2} \mathrm{HMBEN}\right)$, bis(2-hydroxy3.Isopropyl benzaldehyde) 1,2-diaminoethane $\left(\mathrm{H}_{2} \mathrm{HPBEN}\right)$, bis(3-tert,butyl-2-hydroxy benzaldehyde) 1,2-diaminoethane $\left(\mathrm{H}_{2} \mathrm{BHBEN}\right)$, were synthesized by the procedure as given below.

All the Schiff bases were synthesized by condensing the respective aldehyde with diamine (in 2:1 ratio) in ethanol (rectified). The mixture was refluxed for 3hours on cooling crystals were separated out, which were filtered washed with water and recrystallized from ethanol. The characteristics of all synthesized Schiff bases are given in TABLE-1.

\section{Synthesis of $\mathrm{Cr}$ (III)Schiff Base Complexes}

Schiff base complexes were synthesized by taking chromium tri chloride + ligand (SALEN) + sodium carbonate 1:1:3/4 molar ratio using solvent system ethylene glycol + water + methanol in (1:1:3 $\mathrm{w} / \mathrm{w}$ ratio) and the contents were refluxed for about 5 hours and color was checked. After the completion of reaction the contents were concentrated which results in a solid which was filtered off and dissolved in sodium hydroxide solution, yellow needle like crystals of [Cr $\left.(\mathrm{SALEN})\left(\mathrm{H}_{2} \mathrm{O}\right)_{2}(\mathrm{Cl})\right]$ was obtained after nutralization using dil. hydrochloric acid. Similar procedure was adopted for the preparation of other Chromium(III) Schiff bases complexes.

\section{Measurements}

The Schiff base ligand and its complexes under investigation were subjected to $(\mathrm{C}, \mathrm{H}$ and $\mathrm{N})$ elemental analysis which performed at analytic unit of the D.R.D.E. Gwalior using CARLO-ERBA and Haereus C, H, N, O-rapid elemental analyser. Melting points were measured in "TEMPO" electrically operated melting point apparatus. For conductance measurement solutions $\left(10^{-3} \mathrm{M}\right)$ of metal complexes were prepared in dimethyl formamide. The conductivity of the solution was measured using a digital conductivity meter.

The magnetic moment measurements were carried out at room temperature using a Gouy balance on a Brucker magnet B-E15. The electronic spectra of complexes has been recorded in dimethyl formamide using SHIMADZU UV- 160A UV visible spectrophotometer in the range $200-800 \mathrm{~nm}$.

\section{RESULTS AND DISCUSSION}

\section{Elemental Analysis}

The complexes were subjected to chemical analysis and results fall within the range expected for the proposed structures. It is seen that experimentally observed analytical values for $\mathrm{C}, \mathrm{H}$ and $\mathrm{N}$ are in close agreement with the values calculated for the molecular formula assigned to these complexes. 


\section{Molar Conductance}

The molar conductance of these metal complexes in dimethyl formamide $\left(10^{-3} \mathrm{M}\right)$ is listed in TABLE-II. The molar conductivity data for $\mathrm{Cr}$ (III) shows that these complexes behave as 1:1 electrolyte. This behavior for these complexes was expected on the basis of molecular formula assigned to these complexes.

\section{I.R.Spectral Studies}

The IR spectra in the range of $4000-400 \mathrm{~cm}$ ${ }^{1}$ for some of the representative complexes were

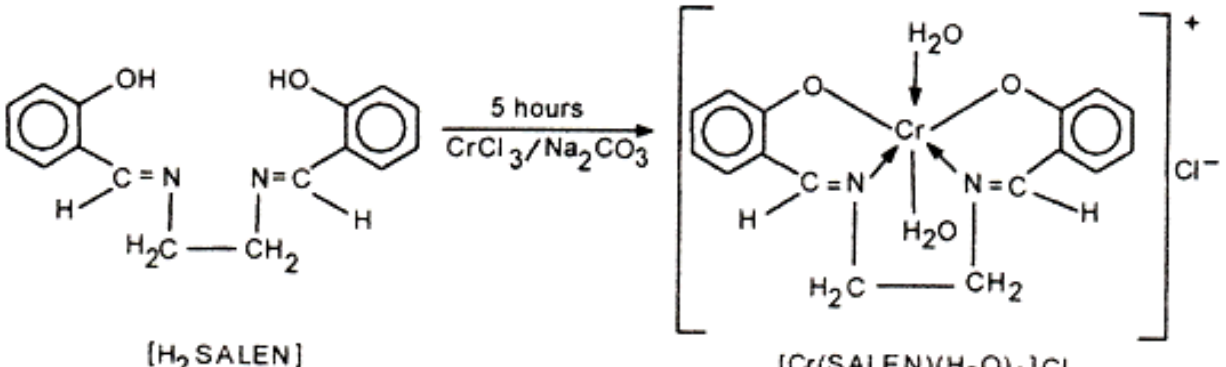

$\left[\mathrm{H}_{2}\right.$ SALEN]

$\left[\mathrm{Cr}(\mathrm{SALEN})\left(\mathrm{H}_{2} \mathrm{O}\right)_{2}\right] \mathrm{Cl}$

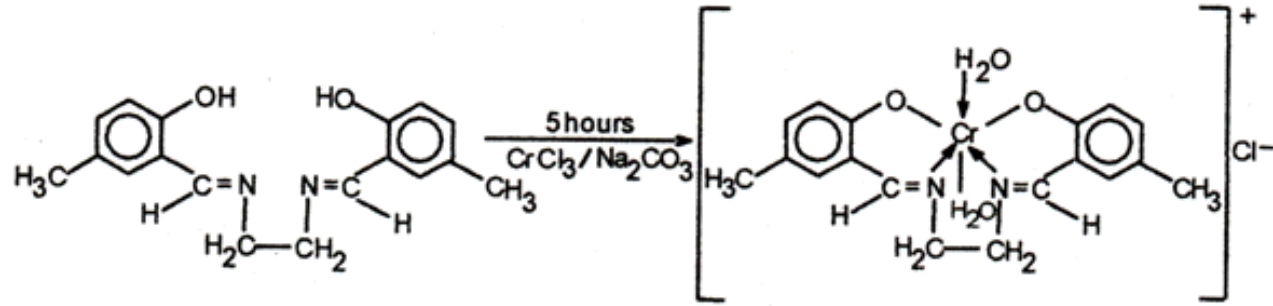

[ $\left.\mathrm{H}_{2} \mathrm{HMBEN}\right]$

$\left[\mathrm{Cr}(\mathrm{HMBEN})\left(\mathrm{H}_{2} \mathrm{O}\right)_{2}\right] \mathrm{Cl}$<smiles>CC(C)c1cccc(/C=N/CC/N=C/c2cccc(C(C)C)c2O)c1O</smiles>

[ $\left.\mathrm{H}_{2} \mathrm{HPBEN}\right]$

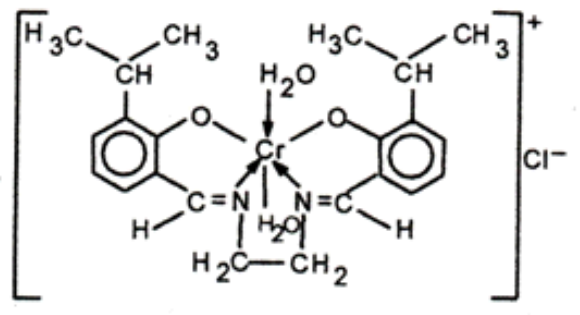

$\left[\mathrm{Cr}(\mathrm{HPBEN})\left(\mathrm{H}_{2} \mathrm{O}\right)_{2}\right] \mathrm{Cl}$<smiles>CC(C)(C)c1cccc(/C=N/CC/N=C/c2cccc(C(C)(C)C)c2O)c1O</smiles>

$\left[\mathrm{H}_{2} \mathrm{BHBEN}\right]$

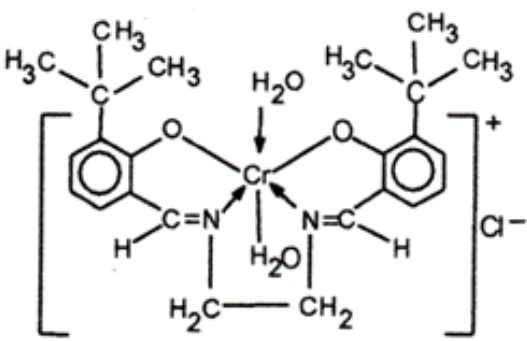

$\left[\mathrm{Cr}(\mathrm{BHBEN})\left(\mathrm{H}_{2} \mathrm{O}\right)_{2}\right] \mathrm{Cl}$

Scheme 
Table 1: Characteristics of schiff bases and $\mathrm{Cr}$ (III) schiff base complexes

\begin{tabular}{|c|c|c|c|c|c|c|}
\hline \multirow{2}{*}{$\begin{array}{l}\text { S. } \\
\text { No. }\end{array}$} & \multirow{2}{*}{$\begin{array}{l}\text { Schiff Bases/ } \\
\text { Complexes }\end{array}$} & \multirow[t]{2}{*}{ Colour } & \multirow{2}{*}{$\begin{array}{l}\text { M.p.l } \\
\text { B.p. }\left({ }^{\circ} \mathrm{c}\right)\end{array}$} & \multicolumn{3}{|c|}{ Analytical Data* } \\
\hline & & & & $\mathrm{C} \%$ & $\mathrm{H} \%$ & $\mathrm{~N} \%$ \\
\hline 1. & $\mathrm{H}_{2}$ (SALEN) & Yellow & 135 & $70.02(71.64)$ & $5.10(5.97)$ & $9.67(10.45)$ \\
\hline 2. & $\mathrm{H}_{2}(\mathrm{HMBEN})$ & Yellow & 149 & 72.59(72.97) & $6.31(6.77)$ & $9.50(9.46)$ \\
\hline 3. & $\mathrm{H}_{2}(\mathrm{HPBEN})$ & Red & - & $74.26(75.00)$ & $7.10(7.95)$ & $7.08(7.95)$ \\
\hline 4. & $\mathrm{H}_{2}(\mathrm{BHBEN})$ & Yellow & - & $75.08(75.79)$ & $8.10(8.42)$ & 7.05(7.73) \\
\hline 5. & {$\left[\mathrm{Cr}(\mathrm{SALEN})\left(\mathrm{H}_{2} \mathrm{O}\right)_{2}\right] \mathrm{Cl}$} & Brown & 172 & $49.01(49.34)$ & $4.0(4.6)$ & $16.89(16.45)$ \\
\hline 6. & {$\left[\mathrm{Cr}(\mathrm{HMBEN})\left(\mathrm{H}_{2} \mathrm{O}\right)_{2}\right] \mathrm{Cl}$} & Brown & 181 & $51.69(51.55)$ & $5.99(5.72)$ & $6.22(6.68)$ \\
\hline 7. & {$\left[\mathrm{Cr}(\mathrm{HPBEN})\left(\mathrm{H}_{2} \mathrm{O}\right)_{2}\right] \mathrm{Cl}$} & $\begin{array}{l}\text { Yellowish } \\
\text { Green }\end{array}$ & 176 & $56.00(55.81)$ & $6.54(6.34)$ & $6.21(5.91)$ \\
\hline 8. & {$[\mathrm{Cr}(\mathrm{BHBEN})(\mathrm{H} 2 \mathrm{O}) 2] \mathrm{Cl}$} & $\begin{array}{l}\text { Whitish } \\
\text { Brown }\end{array}$ & 181 & $58.22(57.48)$ & $6.94(6.48)$ & $5.01(5.58)$ \\
\hline
\end{tabular}

${ }^{*}$ Calculated values are given in \%

Table 2: I.R.Frequency( $\left.\mathrm{cm}^{-1}\right)$ assignments for chromium(III) schiff base complexes

\begin{tabular}{|c|c|c|c|c|c|c|c|}
\hline $\begin{array}{l}\text { S. } \\
\text { No. }\end{array}$ & Complexes & $v \mathrm{C}-\mathrm{H}$ & $v C=N$ & $v \mathrm{C}-\mathrm{O}$ & $v$ & $\begin{array}{c}\text { Molar } \\
\text { Conductivity } \\
\mathrm{Ohm}^{-1} \mathbf{c m}^{2} \mathbf{m o l}^{-1}\end{array}$ & $\begin{array}{c}\text { Magnetic } \\
\text { Moment } \\
\mu_{\mathrm{eff}} / \mathrm{BM}\end{array}$ \\
\hline 1. & {$\left[\mathrm{Cr}(\mathrm{SALEN})\left(\mathrm{H}_{2} \mathrm{O}\right)_{2}\right] \mathrm{Cl}$} & $3200-3010$ & 1630 & 1350 & 764 & 51 & 4.1 \\
\hline 2. & {$\left[\mathrm{Cr}(\mathrm{HMBEN})\left(\mathrm{H}_{2} \mathrm{O}\right)_{2}\right] \mathrm{Cl}$} & $3080-2900$ & 1630 & 1320 & 762 & 67 & 3.6 \\
\hline 3. & {$\left[\mathrm{Cr}(\mathrm{HPBEN})\left(\mathrm{H}_{2} \mathrm{O}\right)_{2}\right] \mathrm{Cl}$} & $3085-2800$ & 1615 & 1310 & 760 & 83 & 3.8 \\
\hline 4. & {$\left[\mathrm{Cr}(\mathrm{BHBEN})\left(\mathrm{H}_{2} \mathrm{O}\right)_{2}\right] \mathrm{Cl}$} & $3140-2820$ & 1610 & 1320 & 760 & 86 & 3.9 \\
\hline
\end{tabular}

recorded. The characteristic bands are given in TABLE-II. The IR spectrum of Chromium(III) complex shows no strong band in region $3500-3200 \mathrm{~cm}^{-1}$ indicating deprotonation of $\mathrm{OH}$ group and its coordination.

In the IR spectrum of $\left[\mathrm{Cr}(\mathrm{SALEN})\left(\mathrm{H}_{2} \mathrm{O}\right)_{2}\right] \mathrm{Cl}$ complex shows bands in the region $3200-3010 \mathrm{~cm}^{-}$ 1 which can be assigned to deprotonation of $\mathrm{OH}$ group and its coordination with metal. The band due to $v \mathrm{C}=\mathrm{N}$ is shifted to $1630 \mathrm{~cm}^{-1}$ and overlapped with $v \mathrm{C}=\mathrm{C}$. A band at $1350 \mathrm{~cm}^{-1}$ to $v \mathrm{C}-\mathrm{O}$ stretching which suggest the involvement of phenolic group in the coordination.

The IR spectra of $\left[\mathrm{Cr}(\mathrm{HMBEN})\left(\mathrm{H}_{2} \mathrm{O}\right)_{2}\right] \mathrm{Cl}$ complex shows band in the region $3080-2900 \mathrm{~cm}^{-}$ ${ }^{1}$ which can be assigned to $\mathrm{v} \mathrm{C}-\mathrm{H}$ stretching. The spectra of the ligand showed bands at 1640 and
$1610 \mathrm{~cm}^{-1}$ which can be assigned to $\mathrm{vC}=\mathrm{N}$ and $v \mathrm{C}=\mathrm{C}$ stretching respectively. The $v \mathrm{C}=\mathrm{N}$ stretching on coordination was found to shift to lower value on coordination $\left(1630 \mathrm{~cm}^{-1}\right)$ and over lapped with $v C=C$ of phenyl ring. The $v \mathrm{C}-\mathrm{O}$ stretching was found to shift to $1320 \mathrm{~cm}^{-1}$ suggesting its involvement in coordination. The absorption band at $762 \mathrm{~cm}^{-1}$ can be assigned to the aromatic vicinal trisubstitution.

The IR spectrum of $\left[\mathrm{Cr}(\mathrm{HPBEN})\left(\mathrm{H}_{2} \mathrm{O}\right)_{2}\right] \mathrm{Cl}$ shows that bands in the region $3520-3000 \mathrm{~cm}^{-1}$ are absent which are observed in the IR spectrum of ligand suggesting deprotonation of $\mathrm{vOH}$ groups and its participation in coordination. Strong peaks in the region $3085-2800 \mathrm{~cm}^{-1}$ can be assigned for $\mathrm{vC}-\mathrm{H}$ stretching vibration. The peak at $1615 \mathrm{~cm}^{-1}$ can be assigned to $v \mathrm{C}=\mathrm{N}$ suggesting its participation in coordination. The absorption band at $1320 \mathrm{~cm}^{-1}$ can be attributed to for $\mathrm{vC}-\mathrm{O}$ stretching mode. 
The $\left[\mathrm{Cr}(\mathrm{BHBEN})\left(\mathrm{H}_{2} \mathrm{O}\right)_{2}\right] \mathrm{Cl}$ complex shows absorption bands in the region $3140-2820 \mathrm{~cm}^{-1}$, which can be assigned to $\mathrm{nC}-\mathrm{H}$ asymmetric stretching vibration of $-\mathrm{CH}_{3}$ and $-\mathrm{CH}_{2}$ groups. Strong bands at $1610 \mathrm{~cm}^{-1}$ can be assigned to $v \mathrm{C}=\mathrm{N}$ suggesting its participation in coordination. The IR spectra also shows strong peaks at $1410 \mathrm{~cm}^{-1}$ and $1460 \mathrm{~cm}^{-1}$ respectively which are due to $\mathrm{nC}-\mathrm{H}$ stretching of tert.butyl group. The peak at $1320 \mathrm{~cm}^{-1}$ can be attributed to $\mathrm{vC}-\mathrm{O}$ group.

\section{Electronic Spectra}

The UV-visible spectra of some representative Schiff base complexes of $\mathrm{Cr}$ (III) were recorded in solvent (dimethyl formamide). The electronic spectra show absorption in the range $550-275 \mathrm{~nm}$ which can be assigned to $\mathrm{n}-\Pi^{*}$ and $\Pi$ - $\Pi^{*}$ transitions. The $\Pi-\Pi^{*}$ transition are suggested to involves molecular orbital $\Pi$ localized at the azomethane linkage. The information regarding the geometry of the complexes could not be ascertained with the observed data.

\section{Magnetic Moment}

The magnetic moment for the $\mathrm{Cr}$ (III) Schiff base complexes is the range 3.6- 4.1 BM indicating the three unpaired electron.

\section{REFERENCES}

1. Dubey, R.K.; Dubey, U.K.; Mishra, C.M. Ind.J.Chem. 2008, 47A, 1208.

2. Thomas, R; , Thomas, K.J.; Parmeshwaram, G. J.Ind.Chem.Soc. 1996, 73, 529.

3. Baleizao, C.; Garcia, H. Chem.Rev. 2006, 106, 9 and 3987.

4. Bailey, A.J.; Griffith, W.P.; Savage, P.D. J.Chem.Soc.Dalton, Trans. 1995, 21, 3537.

5. Ahmad, A.A.; Bengukki, S.A.; Ahshed, O.M. Russian.J.Chem. 2009, 2, 4, 781.

6. Ballistereri, F.P.; Tomaselli, G.A.; Toscana, R.M. Spec.Publ.R.Soc.Chem.1995, 148.

7. Lorber, C.Y.; Paul, I.; Osborn, J.A. Bull.Soc.Chem.Fr. 1996, 133, 755.

8. Dickman, M.H.; Pope, M.T. Chem.Rev. 1994, 94, 569.

9. Jin, R.; Cho, C.S.; Jiang, L.H.; Shim, S.C. Bull.Korean.Chem.Soc. 1996, 17, 657.

10. Bruice, T.C.; Ostovic, D. J.Am.Chem.Soc. 1998, 110, 6906.

11. Khenkin, A.M.; Hill, C.L. J.Am.Chem. Soc. 1993,115, 8178.

12. Fillmore, F. Org. Synth.Oxi.Met.Compd.1986, 41.
13. Tretyakov, V.P.; Zimtseva, G.P.; Min'ko. L.A.; Rudakov, E.S. U.Khim.Zh.1990, 56, 51.

14. Schiff, H. Ann.Suppl. 1964, 3, 343.

15. Gennari. C.; Piarulli, U. Chem.Rev. 2003, 103, 3071.

16. Cozzi, P.G. Chem.Soc.Rev. 2004, 33, 410.

17. Marie, F.R.; Hans, J.S.; Garrigh. Mc.; Dalton, M., Cornac, T.; Daly. A.; Gilheany, M.C.; Dalton, G. J.Mol.Catal.A.Chem. 2005, 231, 205.

18. Shrivastava, H.; Devraj, Y.; Nain, B.U.; J.Inorg.Bio.Chem.2004, 387, 98.

19. Cenicern, G.; Agueda, E.; Porlilla, P.R.; Del, F.; Organ, H.; Blum, C. _Siliusa. Inorg. Chin. Acta.2002, 331, 59.

20. Can-Cheng, G.; He-Ping, Li.; Xiao-Bing Z.; Chin.J.Chem. 2005, 23, 4, 431.

21. Hamuryudan, E.; Bekaroglu, A.Z. O.Monatsh.Chem. 2000, 131, 175.

22. Karaoglan, G.K.; Actiata, U.; Gill, A. Ind.J. Chem. 2007, 46A, 1273.

23. Cimerman, Z.; Galic, N.; Bosner, B. Anal.Chim.Acta. 1997, 343, 145.

24. Ibrahim, M.N.; Sharif, S.E.A. E-J.Chem. 2007, 4, 531. 